\title{
UPAYA MENINGKATKAN ASERTIVITAS MELALUI LAYANAN KONSELING KELOMPOK DENGAN TEKNIK ASERTIF TRAINING PADA SISWA ASUH KELAS X DPIB 2 SMK NEGERI 1 SAMPANG
}

\author{
Syaiful Hidayatullah \\ SMK Negeri 1 Sampang \\ syaifhidayatullah@gmail.com
}

\begin{abstract}
Assertive behavior is important for individuals. Assertive behavior reflects how individuals are able to recognize themselves and be honest in dealing with or interacting with others. Assertive behavior leads individuals to be able to appreciate the expression of positive and negative feelings of themselves and others and to be able to exercise self-control without guilt. The purpose of this study was to determine the efforts to increase assertiveness through group counseling services with assertive training techniques for students. In this study, the research subjects were students who had a low level of assertiveness in class X DPIB 2 SMK Negeri 1 Sampang. This research took place in two cycles. The data collection technique used a student activeness questionnaire. The data analysis method used to analyze the level of success or the percentage of giving reinforcement to student assertiveness was done by providing an evaluation questionnaire. From the results of cycles I and II, there was an increase in the criteria for rigor from "low" to "medium" and "high". Group counseling with assertive training techniques can increase student assertiveness.
\end{abstract}

\begin{abstract}
ABSTRAK
Perilaku asertif menjadi hal penting yang dimiliki individu. Perilaku asertif mencerminkan bagaimana individu mampu untuk mengenali diri sendiri dan jujur dalam berhubungan atau berinteraksi dengan orang lain. Perilaku asertif mengarahkan individu untuk mampu menghargai ekspresi dari perasaan positif dan negative diri sendiri maupun orang lain dan mampu untuk melakukan control diri tanpa rasa bersalah. Tujuan Penelitian ini bertujuan untuk mengkaji Upaya peningkatkan Asertivitas Melalui Layanan Konseling Kelompok Dengan Teknik Asertif Training Pada Siswa. Dalam Penelitian ini subjek penelitian adalah siswa yang memiliki tingkat asertivitas rendah di kelas X DPIB 2 SMK Negeri 1 Sampang. Penelitian ini berlangsung dalam dua siklus. Teknik pengumpulan data menggunakan angket assetivitas siswa. Metode analisis data yang digunakan menganalisis tingkat keberhasilan atau persentase pemberian reinforcement terhadap Asertivitas siswa dilakukan dengan cara memberikan evaluasi angket. Dari hasil siklus I dan II terdapat peningkatan kriteria asertivitas dari "rendah" ke "sedang" dan "tinggi". Konseling kelompok dengan teknik assertive training dapat meningkatkan assertivitas siswa.
\end{abstract}

Kata Kunci perilaku asertif, asertive training, konseling kelompok

Cara mengutip: Hidayatullah, S. (2020). Upaya Meningkatkan Asertivitas Melalui Layanan Konseling Kelompok Dengan Teknik Asertif Training Pada Siswa Asuh Kelas X DPIB 2 SMK Negeri 1 Sampang. Nusantara of Research : Jurnal Hasil-Hasil Penelitian Universitas Nusantara PGRI Kediri (eJournal), 7(2), 99-105. https://doi.org/10.29407/nor.v7i2.15061

\section{PENDAHULUAN}

Perilaku asertif menjadi hal penting ketika berinteraksi dengan orang lain. Sikap asertif perlu dimiliki oleh setiap orang karena perilaku asertif merupakan suatu perilaku dimana 
seseorang dituntut utuk bersikap jujur terhadap diri sendiri dan memperlihatkan ekspresi yang sesuai dengan kondisi saat itu, baik sesuai dengan perasaan, pendapat atau pikirannya dan hal-hal yang menjadi kebutuhannya (Pratanti: 2007).

Seseorang yang berperilaku pasif selalu berpikir bahwa gagasan dan pendapat yang ia kemukakan dalam percakapan akan menuai respons yang negatif dari orang lain sehingga mereka cenderung memilih tidak berkomentar dan selalu menerima saran dari orang lain. Dalam suatu hubungan dengan orang lain mereka yang memiliki perilaku pasif cenderung gelisah dan khawatir tentang reaksi orang lain kepadanya (Deraishy Luo: 2012).

Sifat pasif (tidak asertif) biasanya dimiliki oleh seseorang yang cenderung pendiam dan pemalu, bisa juga disebabkan oleh lingkungan baru yang membuat dia canggung dan tidak nyaman untuk bersosialisasi. hal tersebut juga bisa terjadi dikalangan siswa, terutama siswa SMK kelas $X$ yang baru beradaptasi dengan suasana dan lingkungan yang baru. Dalam pengertian yang lebih luas, pasif (tidak asertif) adalah perilaku seseorang untuk menghindari konflik yang akan dihadapinya. Orang yang pasif atau tidak asertif selalu mengungkapkan halhal yang tidak sesuai dengan apa yang mereka inginkan, hal tersebut dikarenakan mereka takut orang lain tidak sependapat dengan apa yang mereka pikirkan. Dalam kenyataannya individu yang berperilaku pasif cenderung bersembunyi dari orang lain untuk menunggu orang tersebut memulai percakapan terlebih dahulu, dan mereka selalu mendahulukan keinginan dan kepentingan orang lain didepan keinginannya sendiri dan cenderung berpikir negatif terhadap pemikiran dan keinginannya sendiri.

Banyak perilaku merugikan diri yang terjadi jika seorang anak mempunyai perilaku pasif, mereka cenderung berpikir apa yang dilakukannya selalu salah dan tampak tidak tegas dalam menyikapi permasalahan yang dihadapinya. Mereka juga selalu menghindari percakapan-percakapan antar individu sehingga akan berpengaruh terhadap perkembangan sosialnya dalam bersosialisasi di bermasyarakat. Perilaku merugikan lainnya dari seseorang yang tidak asertif ialah selalu merasa tidak mampu dan tidak pernah menuntut walaupun merugikan dirinya, dan takut tampil didepan orang banyak. Rizki Mutia Faradita, Yessy Elita, Rita Sinthia (2018) Berpendapat nbahwa bersikap non assertif dapat membahayakan diri sendiri bila dibiarkan karena salah satu pihak merasa dirinya telah dimanfaatkan oleh pihak lain, tidak menyelesaikan masalah yang dihadapi, bahkan dapt menimbulkan stress dan kecemasan yang berlebihan, siswa yang berperilaku tidak asertif biasanya cenderung dirugikan oleh temantemannya. Banyak siswa yang memilih untuk tidk berperilaku aserif karena takut dijauhi oleh temannya.

Seseorang yang berperilaku pasif biasanya mengalami gangguan-gangguan diantaranya seperti lemahnya seseorang untuk bisa berkata "tidak" terhadap seseorang yang meminta sesuatu. Hal ini merupakan ciri-ciri yang di tampakkan seseorang berperilaku pasif, mereka cenderung tidak bisa berkata "tidak" (menolak) terhadap seseorang yang meminta bantuan di luar kemampuan yang dimilikinya, individu yang seperti ini biasanya takut mengutarakan penolakan karena tidak ingin melukai hati seseorang yang telah memintanya bantuan. Kemudian Seseorang yang tidak yakin akan haknya dalam situasi tersebut. Menurut Mio Hiling (2012) orang asetif mengarah kepada orang yang mampu untuk memahami dan 
yakin terhadap hak diri sendiri maupun orang lain sehingga memunculkan perilaku asertif. Terakhir adalah merasa gugup dan tidak tau harus berperilaku ketika dihadapkan pada situasi yang baru dan terlihat asing di depannya. Seseorang yang mempunyai perilaku pasif selalu terkekang dan tidak mempunyai kesempatan dimasa lalu untuk menempatkan perilaku yang sesuai dengan apa yang dibutuhkan, sehingga ketika dihadapkan oleh situasi-situasi yang baru, mereka tidak tau cara berperilaku yang sesuai dengan keadaannya atau merasa gugup karena kurangnya ketegasan dan percaya diri yang dimilikinya.

Konseling kelompok merupakan suatu upaya pemberian bantuan kepada siswa melalui kelompok untuk mendapatkan informasi yang berguna agar dapat menyelesaikan masalah yang dihadapi, mampu menyusun rencana, membuat keputusan yang tepat, mengembangkan pemahaman terhadap diri sendiri, orang lain, dan lingkungan dalam membentuk perilaku yang lebih efektif dengan menggunakan dinamika kelompok. Konseling kelompok dapat dimaknai sebagai suatu upaya guru pembimbing membantu memecahkan masalah-masalah pribadi yang dialami oleh masing-masing anggota kelompok melalui kegiatan kelompok agar tercapai perkembangan yang optimal. Dalam penelitian kali ini konseling kelompok digunakan untuk membantu siswa memeahkan masalah asertivitas dengan teknik asertif training.

Secara khusus, karena layanan konseling kelompok berfokus pada masalah pribadi individu peserta layanan, maka layanan konseling kelompok yang insentif dalam upaya pemecahan masalah tersebut, para peserta memperoleh dua tujuan yaitu : pertama, berkembangnya perasaan, pikiran, persepsi, wawasan dan sikap terarah kepada tingkah laku khususnya, bersosialisasi dan berkomunikasi. Kedua, terpecahnya masalah individu yang bersangkutan dan diperolehnya imbas pemecahan masalah tersebut (Afrizhal; 2016).

Berdasarkan uraian pada latar belakang diatas, rumusan masalah dalam PTBK ini adalah "Apakah layanan konseling kelompok dengan teknik asertif training dapat meningkatkan asertivitas siswa X DPIB 2 SMK Negeri 1 Sampang”. Penelitian ini bertujuan untuk mengkaji Upaya peningkatkan Asertivitas Melalui Layanan Konseling Kelompok Dengan Teknik Asertif Training Pada Siswa Asuh Kelas X DPIB 2 SMK Negeri 1 Sampang.

\section{METODE}

Dalam Penelitian Tindakan Bimbingan Konseling ini subjek penelitian adalah siswa yang memiliki tingkat asertivitas yang rendah didalam kelas X DPIB 2 SMK Negeri 1 Sampang. Sampel dalam penelitian tindakan kelas ini menggunakan purposive sampling, dimana dalam pengambilan sample peneliti mengambil sample berdasarkan kriteria tertentu. Kriteria yang digunakan dalam pengambilan sample penelitian tindakan bimbingan konseling ini adalah siswa yang memiliki sikap asertivitas yang rendah X DPIB 2 SMKN 1 Sampang dengan angket asertivitas siswa menggunakan skala likert. Pada penelitian tindakan bimbingan konseling ini, peneliti akan mengguanakan 4 orang peserta didik yang memiliki sikap asertivitas rendah yang akan diberikan treetment konseling kelompok dengan teknik pelatihan asertif. Penelitian ini Bertempat di Kelas X DPIB 2 SMK Negeri 1 Sampang dan Penelitian dilaksanakan pada 
semester ganjil tahun ajaran 2020-2021 antara bulan juli 2020 sampai dengan bulan desember 2020.

Desain Penelitian Tindakan Bimbingan dan Konseling meliputi perencanaan, pelaksanaan tindakan, observasi terhadap pelaksanaan tindakan dan refleksi. Pada siklus I perencanaan tindakan pertama adalah pengumpulan data dengan menggunakan angket asertivitas siswa, kemudian pelaksanaan rencana tindakan selanjutnya adalah tahapan penyelesaian masalah awal siswa menggunakan konseling kelompok dengan teknik Pelatihan asertif, Observasi dan evaluasi, kemudian analisa dan refleks yang dilakukan guru Bimbingan dan Konseling untuk mengetahui bagaimana pelaksanaan penelitian tindakan, kelemahan proses layanan. Pada siklus II dilaksanakan atas dasar bahan refleksi siklus I. Jika masih ada permasalahan baru yang muncul maka dibuatkan perencanaan tindakan ke-2, lalu pelaksanaan tindakan ke-2. setelah itu, diamati, direfleksi dan dievaluasi apakah sudah ada perubahan kearah perbaikan atau belum. jika tidak memerlukan perbaikan berarti siklus sudah selesai dilaksanakan dan hasil tindakan sudah dilakukan siswa

Dalam metode analisis ini, data yang didapatkan dalam proses pengembangan, yaitu data kuantitatif. Data kuantitatif yang diperoleh dalam proses penelitian ini berupa skor hasil penilaian angket respon siswa, lembar observasi keterlaksanaannya tindakan reinforcement. Angket respon siswa digunakan untuk mengukur kepraktisan produk yang dikembangkan. Penggunaan angket menganalisis tingkat keberhasilan atau persentase pemberian reinforcement terhadap Asertivitas siswa dilakukan dengan cara memberikan evaluasi angket.

Hasil pengumpulan data oleh peneliti didapatkan dari hasil asesmen pada siklus pertama dan siklus ke dua, hasil dari kedua siklus tersebut digunakan untuk mengambil sebuah kesimpulan bahwa konseling kelompok dengan teknik assertive training dapat meningkatkan assertivitas siswa kelas X DPIB 2 SMK Negeri 1 Sampang.

\section{HASIL}

Data yang diperloleh dari hasil angket perilaku asertif siswa ditemukan bahwa masih terdapat peserta didik di kelas X DPIB 2 SMK Negeri 1 Sampang yang masih mempunyai tingkat asertivitas yang rendah. Untuk menentukan seberapa rendah sikap asertif yang dimiliki siswa peneliti menggunakan lembar observasi dengan jumlah 25 butir item. Observasi dilakukan pada hari Jum'at, Tanggal 16 Oktober 2020 menggunakan media google form dengan tema Asertivitas siswa. dibawah ini.

Skor Asertivitas siswa yang diperoleh dari observasi tahap awal terdapat pada tabel

Tabel 1. Skor assertivitas siswa pra siklus

\begin{tabular}{|c|c|c|c|}
\hline No & Nama & Hasil Observasi Pra Siklus & Kriteria Asertivitas \\
\hline 1. & SR & 59 & Sedang \\
\hline 2. & SM & 55 & Sedang \\
\hline 3 & $N Q$ & 50 & Sedang \\
\hline 4 & UTFY & 40 & Rendah \\
\hline 5 & SBH & 65 & Tinggi \\
\hline 6 & AFF & 65 & Tinggi \\
\hline 7 & MARS & 47 & Sedang \\
\hline
\end{tabular}


Trisno

Efektifitas Konseling Eklektif dengan Perilaku Attending untuk Mengurangi Masalah Belajar Siswa Kelas IX...

\begin{tabular}{|c|c|c|c|}
\hline No & Nama & Hasil Observasi Pra Siklus & Kriteria Asertivitas \\
\hline 8 & MFM & 48 & Sedang \\
\hline 9 & DN & 64 & Tinggi \\
\hline 10 & AS & 54 & Sedang \\
\hline 11 & MSNA & 59 & Sedang \\
\hline 12 & AP & 61 & Tinggi \\
\hline 13 & MRS & 49 & Sedang \\
\hline 14 & MR & 49 & Sedang \\
\hline 15 & DKS & 46 & Sedang \\
\hline 16 & IM & 36 & Rendah \\
\hline 17 & SR & 67 & Tinggi \\
\hline 18 & PD & 35 & Rendah \\
\hline 19 & MFHR & 54 & Sedang \\
\hline 20 & RA & 31 & Rendah \\
\hline
\end{tabular}

Dari data tersebut, dapat diperoleh bahwa terdapat 4 orang siswa yang termasuk dalam kategori asertivitas rendah, 11 termasuk katagori sedang, dan 5 dalam kategori tinggi. Untuk mengatasi permasalahan siswa yang memiliki tingkat asertivitas yang rendah, peneliti mencoba menerapkan Teknik Aserif Training (Pelatihan Asertif) dengan layanan Bimbingan Kelompok di siklus pertama penelitian tindakan bimbingan konseling ini. Teknik asertif training dalam Konseling kelompok ini dipilih karena dengan proses tersebut siswa yang mempunyai tingkat asertivitas yang rendah akan berlatih menggunakan teknik tersebut untuk memperbaiki sikap asertif yang rendah menjadi tinggi.

Tabel 2. Skor assertivitas siswa siklus 1

\begin{tabular}{|c|c|c|c|}
\hline No & Nama & Hasil Observasi Siklus 1 & Kriteria Asertivitas \\
\hline 1. & IM & 50 & Sedang \\
\hline 2. & PD & 40 & Rendah \\
\hline 3 & UTFY & 60 & Sedang \\
\hline 4 & RA & 40 & Rendah \\
\hline
\end{tabular}

Dari hasil observasi siklus 1 diatas, pemberian tindakan Konseling kelompok menggunakan teknik aserif training pada siswa yang mempunyai tingkat asertivitas rendah meningkatkan 2 orang siswa yankni IM dan UTFY yang semula mempunyai kriteria rendah, menjadi kriteria sedang. Kemudian dua orang lainnya masih dalam kriteria rendah yakni IM dan RA. Dengan hasil tersebut peneliti melakukan perbaikan dalam siklus kedua. Dari hasil perbaikan dan peberian treatmen di siklus ke dua ini, diperoleh hasil sebagai berikut.

Tabel 3. Skor assertivitas siswa siklus 2

\begin{tabular}{|c|c|c|c|}
\hline No & Nama & Hasil Observasi Siklus 1 & Kriteria Asertivitas \\
\hline 1. & IM & 70 & Sedang \\
\hline 2. & PD & 60 & Sedang \\
\hline 3 & UTFY & 80 & Tinggi \\
\hline 4 & $\mathrm{RA}$ & 60 & Sedang \\
\hline
\end{tabular}

Dari tabel hasil observasi tentang asertivitas siswa menggunakan konseling kelompok dengan teknik asserive training ini tampak beberapa peningkatan dalam hal asertivitas yang dimiliki siswa. Dalam siklus ke dua pendekatan lebih ditekankan pada siswa yang memiliki tingkat asertivitas rendah dengan memberikan pemahaman dengan media film pendek dan pelatihan tentang asertivitas dengan teknik pelatihan asertif.

Dari dua orang siswa tersebut, PD yang memiliki kriteria "rendah" disiklus pertama, kini meningkat menjadi "sedang" dalam siklus ke dua ini. Sementar RA juga mendapatkan hasil yang sama di siklus kedua ini dari "rendah" menjadi "sedang". Ada kenaikan juga yang dialami oleh peserta didik lain, UTYF yang dalam siklus 1 dalam kriteria "sedang" menjadi "tinggi", 
sementara IM masih dalam kategori "sedang" meskipun terdapan peningkatan skor. Berikut ini adalah peningkata asertivitas siswa per siklus.

Tabel 1.3. Skor assertivitas siswa per siklus

\begin{tabular}{lllcccc}
\hline \multirow{2}{*}{ No } & Nama & Pra Siklus & \multicolumn{2}{c}{ Siklus 1 } & \multicolumn{2}{c}{ Siklus 2 } \\
& Kriteria & Skor & Kriteria & Skor & Kriteria \\
\hline 1. & IM & Rendah & 50 & Sedang & 70 & Sedang \\
2. & PD & Rendah & 40 & Rendah & 60 & Sedang \\
3. UTFY & Rendah & 60 & Sedang & 80 & Tinggi \\
4. & RA & Rendah & 40 & Rendah & 60 & Sedang \\
\hline
\end{tabular}

PEMBAHASAN

Penelitian tindakan bimbingan konseling dengan menggunakan dua siklus ini dilakukan untuk mengetahui apakah teknik assertive training dalam konseling kelompok dapat meningkatkan asertivitas siswa kelas X DPIB 2 SMK Negeri 1 Sampang. Dari tabel diatas dapat diketahui peningkatan skor dan kriteria siswa mulai dari pra siklus sebelum dilakukan tindakan dan sesudah dilakukan tindakan pada siklus pertama dan siklus kedua. Dari hasil siklus pertama pemberian tindakan Konseling kelompok menggunakan teknik aserif training pada siswa yang mempunyai tingkat asertivitas rendah meningkatkan 2 orang siswa yankni IM dan UTFY yang semula mempunyai kriteria rendah, menjadi kriteria sedang. Kemudian dua orang lainnya masih dalam kriteria rendah yakni IM dan RA.

Di siklus kedua dua orang siswa tersebut, PD yang memiliki skor 40 di siklus pertama, kini meningkat menjadi 60 dalam siklus ke dua ini. Sementar RA juga mendapatkan hasil yang sama di siklus kedua ini dari skor 40 menjadi 60. Ada kenaikan juga yang dialami oleh peserta didik lain, UTYF yang dalam siklus 1 dalam kriteria "sedang" menjadi "tinggi", sementara IM masih dalam kategori "sedang" meskipun terdapan peningkatan skor dari 50 menjadi 60.

Dari hasil yang tertera diatas menunjukkan dengan konseling kelompok menggunakan teknik assertive training, terdapat peningkatan asertivitas siswa kelas X DPIB 2 SMK Negeri 1. Terbukti sesuai dengan penelitian sebelumnya pada (Rizki Mutia Faradita, Yessy Elita, Rita Sinthia, 2018:58-66). Ada pengaruh dari treatment (perlakuan) menggunakan konseling kelompok, serta efektif dengan menggunakan teknik assertive training dalam meningkatkan kemampuan asertivitas siswa. Hal ini dapat dibuktikan dari hasil analisis data yang menyebutkan bahwa Ho ditolak yang berarti terdapat peningkatan kemampuan asertivitas setelah diberikan konseling kelompok dengan teknik assertive training.

\section{KESIMPULAN DAN SARAN}

Berdasarkan hasil penelitian tindakan bimbingan konseling yang telah dilaksanakan dalam dua siklus menggunakan konseling kelompok dikelas X DPIB 2 SMK Negeri 1 Sampang, mendapati bahwa penerapan teknik assertive training dengan konseling kelompok mampu meningkatkan asertivitas siswa.

Dalam penelitian tindakan bimbingan konseling ini tentunya masih jau dari kata sempurna. Maka dari itu peneliti mengemukakan saran untuk semua pihak yang terkait dari pihak sekolah, guru bimbingan konseling, dan peneliti untuk terus mengembangkan teori dan teknik bimbingan konselig untuk membantu peserta didik mencapai tuugas-tugas perkembangannya di lingkungan sekolah maupun di lingkungan masyarakat. 
Trisno

Efektifitas Konseling Eklektif dengan Perilaku Attending untuk Mengurangi Masalah Belajar Siswa Kelas IX...

\section{DAFTAR RUJUKAN}

Afrizhal. 2016. Pengertian Dan Tujuan Konseling Kelompok (Online),

(http://afriezhael.blogspot.com/2016/10/pengertian-dan-tujuan-konseling-

kelompok.html), diakses 15/10/20 pukul 08:37.

Deraishy Luo. 2012. Makalah Perilaku Asertif (Online), (http://deraishyblogdedhe.blogspot.com/2012/05/makalah-perilaku-asertif.html) diakses 16/10/20 pukul 16:15.

Faradita, Rizki Mutia, Yessy Elita, Rita Sinthia (2018) Pengaruh Konseling Kelompok Dengan Teknik Assertive Training Terhadap Kemampuan Asertivitas Siswa Kelas Viii 8 Smp Negeri 18 Kota Bengkulu. Jurnal Ilmiah Bimbingan dan Konseling, Volume 1 Nomor 22018 FKIP Universitas Bengkul. 1(2):58-66.

Mio Hilig. 2011. "ASERTIVITAS", (online),

(http://ururureaoka.blogspot.com/2011/10/asertivitas.html) , diakses 16/10/20 pukul 16:15.

Pratanti. 2007. "Tips bersikap asertif', (online), (http://pratanti.wordpress.com/2007/10/26/tipsbersikap-asertif/), diakses tanggal 16/10/20 pukul 10:00

Rahardjo, Susilo \& Gudnanto. (2011). Pemahaman Individu Teknik Non Tes. Kudus: Nora Media Enterprise. 